\title{
Blood eosinophils predict inhaled fluticasone response in bronchiectasis
}

\author{
To the Editor:
}

The use of inhaled corticosteroids (ICS) in patients with bronchiectasis is a matter of debate [1]. International registries report up to $42 \%$ of bronchiectasis patients receiving ICS, although several guidelines recommend their prescription only in the presence of specific comorbidities (e.g. allergic bronchopulmonary aspergillosis (ABPA), asthma, COPD, and inflammatory bowel disease) or of eosinophilic inflammation [2,3]. Assessment of eosinophil counts in sputum is not considered, to date, a standard of care. Blood eosinophils have been shown to be a predictor of ICS response in COPD and asthma $[4,5]$. The identification of a specific population of bronchiectasis patients who might respond to ICS is key. Response to ICS can be measured in bronchiectasis patients evaluating not only the reduction of exacerbations but also the improvement of their quality of life (QoL). We hypothesised that bronchiectasis patients with a high blood eosinophil count can benefit from ICS in terms of a clinically meaningful improvement of QoL.

An unplanned, post hoc analysis of a randomised, double-blind, controlled, study aimed at evaluating the impact of ICS on QoL in bronchiectasis patients was conducted. Details of the study are reported elsewhere [6]. Adults with clinically and radiologically significant bronchiectasis were enrolled in a single centre in Spain. Patients with cystic fibrosis, as well as those with concomitant asthma or ABPA, were excluded. Patients in stable clinical conditions (4 weeks out of an exacerbation) were randomised to a 6-month treatment with either $250 \mu \mathrm{g}$ twice daily or $500 \mu \mathrm{g}$ twice daily inhaled fluticasone propionate (FP) or no treatment. The primary endpoint was a clinically significant change ( $\geqslant 4$ points) in the St George's Respiratory Questionnaire (SGRQ) total score after 6 months of therapy. Four study groups were considered, based on both the percentage of blood eosinophils at baseline $(<3 \%$ : low blood eosinophils (LowEos group) versus $\geqslant 3 \%$ : high blood eosinophils (HighEos group)) and the exposure to FP (no treatment versus treatment with FP). Following the poor scientific evidence on the cut-off value of eosinophils in bronchiectasis studies, the $3 \%$ eosinophil threshold has been arbitrarily chosen to be the median percentage value in our cohort. Furthermore, the same analysis was conducted using the 150 cells $\mu \mathrm{L}^{-1}$ cut-off of the absolute eosinophils count $\left(<150\right.$ cells $\mu \mathrm{L}^{-1}$ : LowEos group versus $\geqslant 150$ cells $\mu \mathrm{L}^{-1}$ : HighEos group). Finally, a sensitivity analysis was conducted excluding patients with a diagnosis of COPD.

Among the 86 patients enrolled in the original study, 42 (48.8\%) were in the HighEos and $44(51.2 \%)$ in the LowEos group. In the HighEos group, 13 (31.0\%) were not treated, whereas 29 (69.1\%) were treated with FP. In the LowEos group, 16 (36.4\%) were not treated, whereas 28 (63.6\%) were treated with FP. No statistically significant differences were found between the four study groups at baseline in terms of age, gender, treatment with FP and SGRQ values (table 1). No statistically significant differences were also found after the exclusion of patients with COPD. Among the entire study population, a statistically significant reduction ( $\geqslant 4$ points) of the SGRQ after 6 months of FP was found in the HighEos group between those who were versus were not treated with FP $(15$ (51.7\%) versus $0(0.0 \%) ; \mathrm{p}=0.0001)$ (table 1 ). In the HighEos group, the median (interquartile range (IQR)) SGRQ total change was $-4.1(-9.7 ; 0.4)$ and $1.6(0.7 ; 3.1)$ in those treated and not treated with FP $(\mathrm{p}=0.002)$. In the HighEos group, the proportion of individuals with a modified Medical Research Council (mMRC) scale of 3-4 at 3 months of follow-up was significantly higher in those not treated with FP (23.1\% versus $0.0 \% ; \mathrm{p}=0.03)$, and a higher exacerbation rate was found in those who were not treated versus those who were treated with FP, although there was no statistically significant difference. No statistically significant differences were found for the mean forced expiratory volume in $1 \mathrm{~s}\left(\mathrm{FEV}_{1}\right)$ at 6 months in the HighEos group. No statistically

@ERSpublications

6-month treatment with inhaled fluticasone propionate significantly improved quality of life in bronchiectasis patients who show a blood eosinophil counts $\geqslant 3 \%$. https://bit.ly/3fsn 4 na

Cite this article as: Aliberti S, Sotgiu G, Blasi F, et al. Blood eosinophils predict inhaled fluticasone response in bronchiectasis. Eur Respir J 2020; 56: 2000453 [https://doi.org/10.1183/13993003.00453-2020]. 
TABLE 1 Baseline characteristics and outcomes of the four study groups

\begin{tabular}{|c|c|c|c|c|c|c|}
\hline \multicolumn{7}{|c|}{ Baseline characteristics } \\
\hline \multirow[t]{2}{*}{ Variable } & \multicolumn{2}{|c|}{ LowEos group (Eos $<3 \%$ ) } & \multirow[t]{2}{*}{ p-value } & \multicolumn{2}{|c|}{ HighEos group (Eos $\geqslant 3 \%$ ) } & \multirow[t]{2}{*}{ p-value } \\
\hline & $\begin{array}{c}F P+ \\
n=28\end{array}$ & $\begin{array}{c}\text { FP- } \\
n=16\end{array}$ & & $\begin{array}{c}F P+ \\
n=29\end{array}$ & $\begin{array}{l}\text { FP- } \\
n=13\end{array}$ & \\
\hline Age years & $73(68.5-78.0)$ & $69.5(68-75)$ & 0.35 & $67(63-73)$ & $72(66-75)$ & 0.09 \\
\hline Males & $20(71.4)$ & $8(50.0)$ & 0.16 & $18(62.1)$ & 9 (69.2) & 0.65 \\
\hline Idiopathic & $15(53.6)$ & 6 (37.5) & 0.38 & $12(41.4)$ & $4(30.8)$ & 0.82 \\
\hline Post-infective & $7(25.0)$ & $4(25.0)$ & & 9 (31.0) & $7(53.9)$ & \\
\hline Post-tuberculous & 5 (17.9) & $3(18.8)$ & & $6(20.7)$ & $2(15.4)$ & \\
\hline Other & $1(3.6)$ & $3(18.9)$ & & $2(7.0)$ & & \\
\hline Purulent sputum & $10(35.7)$ & $7(43.8)$ & 0.60 & 9 (31.0) & $3(23.1)$ & 0.72 \\
\hline BORG & $3(2-5)$ & $3(2.5-4.5)$ & 0.97 & $3(2-5)$ & $3(2-5)$ & 0.92 \\
\hline Gram-positive PMM & $6(21.4)$ & $0(0.0)$ & 0.07 & $3(10.3)$ & $1(7.7)$ & 1.00 \\
\hline \multicolumn{7}{|l|}{ mMRC basal } \\
\hline 0 & $2(7.1)$ & $3(18.8)$ & 0.56 & $1(3.5)$ & $1(7.7)$ & 0.58 \\
\hline 1 & $6(21.4)$ & $1(6.3)$ & & $7(24.1)$ & 5 (38.5) & \\
\hline 2 & $15(53.6)$ & 9 (56.3) & & $13(44.8)$ & 5 (38.5) & \\
\hline 3 & $4(14.3)$ & $3(18.8)$ & & $8(27.6)$ & $2(15.4)$ & \\
\hline 4 & $1(3.6)$ & $0(0.0)$ & & & & \\
\hline $\begin{array}{l}\text { Exacerbations } \\
\text { post-randomisation }\end{array}$ & $1(0-2)$ & $1(0-1)$ & 0.58 & $1(0-1)$ & $1(1.0-1.5)$ & 0.81 \\
\hline Baseline SGRQ & $42.8(31.6-55.4)$ & $45.8(36.2-60.6)$ & 0.25 & $50.8(33.9-61.5)$ & 41.5 (25.2-51.5) & 0.21 \\
\hline
\end{tabular}

Outcome data stratified by Eos \%

\begin{tabular}{|c|c|c|c|c|c|c|}
\hline Change $S G R Q \geqslant 4$ points & 10 (37.0) & $1(6.7)$ & 0.06 & 15 (51.7) & $0(0.0)$ & 0.001 \\
\hline $\mathrm{FEV}_{1}$ at 6 months $\mathrm{mL}$ & $1524 \pm 369.3$ & $1476 \pm 607.0$ & 0.86 & $1429 \pm 470.5$ & $1404 \pm 212.0$ & 0.90 \\
\hline $\mathrm{FEV}_{1}$ at 6 months $\%$ & $61.4 \pm 19.6$ & $66.4 \pm 19.6$ & 0.59 & $64.8 \pm 19.2$ & $65.6 \pm 17.1$ & 0.93 \\
\hline mMRC (3-4) at 3 months & 5 (17.9) & $2(12.5)$ & 1.0 & $0(0.0)$ & $3(23.1)$ & 0.03 \\
\hline
\end{tabular}

Outcome data stratified by Eos cells $\mu \mathrm{L}^{-1}$

\begin{tabular}{|c|c|c|c|c|c|c|}
\hline \multirow[t]{2}{*}{ Variable } & \multicolumn{2}{|c|}{ LowEos group (Eos $<150$ cells· $\mu \mathrm{L}^{-1}$ ) } & \multirow[t]{2}{*}{ p-value } & \multicolumn{2}{|c|}{ HighEos group (Eos $\geqslant 150$ cells $\mu L^{-1}$ ) } & \multirow[t]{2}{*}{$p$-value } \\
\hline & $\begin{array}{l}\mathrm{FP}+ \\
\mathrm{n}=13\end{array}$ & $\begin{array}{c}\text { FP- } \\
n=10\end{array}$ & & $\begin{array}{l}\mathrm{FP}+ \\
\mathrm{n}=44\end{array}$ & $\begin{array}{c}\text { FP- } \\
n=19\end{array}$ & \\
\hline SGRQ total change* & $-2.5(-5.3$ to +2.7$)$ & $-0.7(-2.0$ to +1.6$)$ & 0.54 & $-3.1(-8.9$ to +2.8$)$ & $+1.6(0.4$ to +4.2$)$ & 0.003 \\
\hline FEV1 at 6 months $\mathrm{mL}$ & $1761.3 \pm 614.3$ & $1260 \pm 538.7$ & 0.14 & $1371.3 \pm 441.0$ & $1610 \pm 393.4$ & 0.21 \\
\hline FEV1 at 6 months $\%$ & $68.4 \pm 19.6$ & $58.5 \pm 15.3$ & 0.33 & $61.4 \pm 20.3$ & $72.6 \pm 18.5$ & 0.21 \\
\hline
\end{tabular}

Data are presented as median (interquartile range), $\mathrm{n}(\%)$ or mean $\pm \mathrm{SD}$, unless otherwise stated. LowEos: low eosinophil; HighEos: high eosinophil; FP: fluticasone propionate; BMI: body mass index; $\mathrm{FEV}_{1}$ : forced expiratory volume in $1 \mathrm{~s}$; CRP: C-reactive protein; PPM: potentially pathogenic microorganism; mMRC: modified Medical Research Council Dyspnea Scale; SGRQ: St George's Respiratory Questionnaire. \#: difference between the 6-month assessment and the baseline value. 
significant improvement of QoL was detected in patients with LowEos when patients who were administered FP were compared with those exposed to placebo (10 (37.0\%) versus 1 (6.7\%); $\mathrm{p}=0.06)$. No statistically significant differences were found for the exacerbation rate, mean $\mathrm{FEV}_{1}$ at 6 months and proportion of MRC 3-4 in the LowEos group. The sensitivity analysis based on the exclusion of patients with concomitant COPD confirmed the above-mentioned findings (change of the SGRQ $\geqslant 4$ points in the HighEos group: $47.4 \%$ in patients treated with FP versus $0.0 \%$ in patients treated with placebo; $\mathrm{p}=0.03$ ). In the HighEos group after exclusion of COPD patients, the median SGRQ total change was $-3.7(-8.5$; $+5.0)$ versus $+1(+0.4 ;+2.7)$ in those treated versus those not treated with FP $(\mathrm{p}=0.02)$.

Using the 150 cells $\mu \mathrm{L}^{-1}$ cut-off of eosinophils absolute count, a statistically significant reduction $\left(\geqslant 4\right.$ points) of the SGRQ after 6 months of FP was found in the HighEos group $\left(\geqslant 150\right.$ cells $\mu \mathrm{L}^{-1} ; \mathrm{n}=63$ patients) between those who were versus were not treated with FP (21 (47.7\%) versus $0(0.0 \%) ; \mathrm{p}=0.0001)$. In the HighEos group, the median (IQR) SGRQ total change was $-3.1(-8.9 ; 2.8)$ and $1.6(0.4 ; 4.2)$ in those treated and not treated with FP $(\mathrm{p}=0.003)$. Significant differences in terms of reduction $(\geqslant 4$ points) of the SGRQ or the median (IQR) SGRQ total change were not found between those who were versus those were not treated with $\mathrm{FP}$ in the LowEos group $\left(<150\right.$ cells $\mu \mathrm{L}^{-1} ; \mathrm{n}=23$ patients). The sensitivity analysis based on the exclusion of patients with concomitant COPD confirmed the above-mentioned findings (change of the SGRQ $\geqslant 4$ points in the HighEos group $\left(\geqslant 150\right.$ cells. $\left.\mu \mathrm{L}^{-1}\right): 43.3 \%$ in patients treated with FP versus $0.0 \%$ in patients treated with placebo; $\mathrm{p}=0.002)$. In the HighEos group $\left(\geqslant 150\right.$ cells $\left.\mu \mathrm{L}^{-1}\right)$ after exclusion of COPD patients, the median SGRQ total change was $-1.1(-8.5 ;+3.5)$ versus $+1(+0.1$; $+4.2)$ in those treated versus those not treated with FP ( $\mathrm{p}=0.03)$.

Main findings of this experience include: 1) 6-month treatment with inhaled FP significantly improved QoL in the subgroup of adults with bronchiectasis with an eosinophil counts either $\geqslant 3 \%$ or $\geqslant 150$ cells $\mu \mathrm{L}^{-1}$; 2) this successful outcome was not found in those with an eosinophil counts $\geqslant 3 \%$ or $\geqslant 150$ cells $\mu \mathrm{L}^{-1}$ and not exposed to FP nor in those with an eosinophil counts $<3 \%$ or $<150$ cells $\mu \mathrm{L}^{-1}$ exposed or not to FP; 3 ) the statistically significant improvement of QoL in those patients with an eosinophil count $\geqslant 3 \%$ or $\geqslant 150$ cells. $\mu \mathrm{L}^{-1}$ treated with FP was confirmed also in pure bronchiectasis patients with neither asthma nor COPD; 4) a proportional difference, although not statistically significant, was shown in terms of lower exacerbation rate was showed in those patients with an eosinophil counts $\geqslant 3 \%$ or $\geqslant 150$ cells $\mu \mathrm{L}^{-1}$ and were treated with $\mathrm{FP}$ in comparison with those not treated.

Data from local experiences as well as those coming from international registries have informed the scientific and clinical communities about a large proportion of bronchiectasis patients receiving ICS with neither a specific physiopathological rationale nor a strong evidence [2]. Routine use of ICS may cause unwanted side effects in bronchiectasis, including adrenal suppression, an increased risk of hospitalisation for respiratory infections and increased risk of non-tuberculous mycobacteriosis [7-9]. However, a specific T2-high endotype has been hypothesised also in bronchiectasis, with patients presenting an eosinophilic inflammation who might respond to biological drugs [10, 11]. Our results should be interpreted as "hypothesis generating", and we are far from proposing changes in the daily clinical practice. Our preliminary findings support the hypothesis that bronchiectasis patients with neither asthma nor ABPA nor COPD, but with high blood eosinophils, might be the ones who respond to ICS treatment in terms of improvement of QoL, and encourage further research looking also at a possible effect in reducing exacerbations.

Different limitations can be recognised for the present study. The unplanned secondary analysis of a single-centre randomised controlled trial might be affected by a poor statistical power, hindering the generalisability of the findings. Two different doses of FP were prescribed during the clinical trial, raising the question of a different efficacy of the two regimens. However, owing to the poor sample size, a stratification of the cohort based on the two dosages would have been underpowered. We found that eosinophils can be a strong predictor of QoL improvement in bronchiectasis, more than in COPD. This finding could be confounded by the open-label nature of our study. In fact, although the original study design was a double-blind controlled trial, it is important to acknowledge that the design was unblinded for the purpose of this post hoc analysis which evaluates ICS versus placebo. This issue might have impacted patients' evaluation of the QoL through the SGRQ. Furthermore, although SGRQ is a highly validated score to measure QoL in patients with chronic respiratory diseases, we now have new, more specific and accurate questionnaires (e.g. QoL-B), not administered at that time, that could be useful for future trials on this topic. Finally, we should acknowledge a low statistical power to detect differences in exacerbation rate due to the low number of exacerbations. Our study was strengthened by a consistency of the results in bronchiectasis patients both with and without COPD, by clinically meaningful improvement of QoL and by a trend also in reducing exacerbations. In conclusion, there are important signals in this secondary analysis that could guide the scientific community in better designing future randomised controlled trials on the use of steroids in light of the value of blood eosinophils. 
Stefano Aliberti $\oplus^{1,2}$, Giovanni Sotgiu $\oplus^{3}$, Francesco Blasi ${ }^{1,2}$, Laura Saderi $\oplus^{3}$, Tomas Posadas $\oplus^{4}$ and Miguel Angel Martinez Garcia ${ }^{4}$

${ }^{1}$ Fondazione IRCCS Ca' Granda Ospedale Maggiore Policlinico, Respiratory Unit and Cystic Fibrosis Adult Center, Milan, Italy. ${ }^{2}$ University of Milan, Dept of Pathophysiology and Transplantation, Milan, Italy. ${ }^{3}$ Clinical Epidemiology and Medical Statistics Unit, Dept of Biomedical Sciences, University of Sassari, Research, Medical Education and Professional Development Unit, AOU Sassari, Sassari, Italy. ${ }^{4}$ Pneumology Dept, Polytechnic and University La Fe Hospital, Valencia, Spain.

Correspondence: Stefano Aliberti, Dept of Pathophysiology and Transplantation, University of Milan, Respiratory Unit and Cystic Fibrosis Adult Center, Fondazione IRCCS Ca' Granda Ospedale Maggiore Policlinico, Via Francesco Sforza 35, 20122 Milan, Italy. E-mail: stefano.aliberti@unimi.it

Received: 27 Feb 2020 | Accepted after revision: 3 May 2020

Conflict of interest: S. Aliberti reports grants and personal fees from Bayer Healthcare, Aradigm Corporation, Chiesi, INSMED and Grifols, personal fees from AstraZeneca, Basilea, Zambon, Novartis, Raptor, Actavis UK Ltd and Horizon, outside the submitted work. G. Sotgiu has nothing to disclose. F. Blasi reports personal fees from AstraZeneca, GSK, Guidotti Malesci, Grifols, Menarini, Novartis, Pfizer, Sanofi and Zambon, grants from Bayer, grants and personal fees from Chiesi and Insmed, outside the submitted work. L. Saderi has nothing to disclose. T. Posadas has nothing to disclose. M.A. Martinez Garcia has received grants and fees from Zambon, Chiesi, Vitalire, Grifols, Novartis and TEVA.

\section{References}

$1 \quad$ Kapur N, Petsky HL, Bell S, et al. Inhaled corticosteroids for bronchiectasis. Cochrane Database Syst Rev 2018; 5: CD000996.

2 Henkle E, Aksamit TR, Barker AF, et al. Pharmacotherapy for non-cystic fibrosis bronchiectasis: results from an NTM Info \& Research Patient Survey and the Bronchiectasis and NTM Research Registry. Chest 2017; 152: $1120-1127$

3 Polverino E, Goeminne PC, McDonnell MJ, et al. European Respiratory Society guidelines for the management of adult bronchiectasis. Eur Respir J 2017; 50: 1700629.

4 Harries TH, Rowland V, Corrigan CJ, et al. Blood eosinophil count, a marker of inhaled corticosteroid effectiveness in preventing COPD exacerbations in post-hoc RCT and observational studies: systematic review and meta-analysis. Respir Res 2020; 21: 3.

5 Pavord ID, Agusti A. Blood eosinophil count: a biomarker of an important treatable trait in patients with airway disease. Eur Respir J 2016; 47: 1299-1303.

6 Martínez-García MA, Perpiñá-Tordera M, Román-Sánchez $\mathrm{P}$, et al. Inhaled steroids improve quality of life in patients with steady-state bronchiectasis. Respir Med 2006; 100: 1623-1632.

7 Holme J, Tomlinson JW, Stockley RA, et al. Adrenal suppression in bronchiectasis and the impact of inhaled corticosteroids. Eur Respir J 2008; 32: 1047-1052.

8 Henkle E, Curtis JR, Chen L, et al. Comparative risks of chronic inhaled corticosteroids and macrolides for bronchiectasis. Eur Respir J 2019; 54: 1801896.

9 Andréjak C, Nielsen R, Thomsen VØ, et al. Chronic respiratory disease, inhaled corticosteroids and risk of non-tuberculous mycobacteriosis. Thorax 2013; 68: 256-262.

10 Rademacher J, Konwert S, Fuge J, et al. Anti-IL5 and anti-IL5R $\alpha$ therapy for clinically significant bronchiectasis with eosinophilic endotype: a case series. Eur Respir J 2020; 55: 1901333.

11 Carpagnano GE, Scioscia G, Lacedonia D, et al. Severe uncontrolled asthma with bronchiectasis: a pilot study of an emerging phenotype that responds to mepolizumab. J Asthma Allergy 2019; 12: 83-90. 